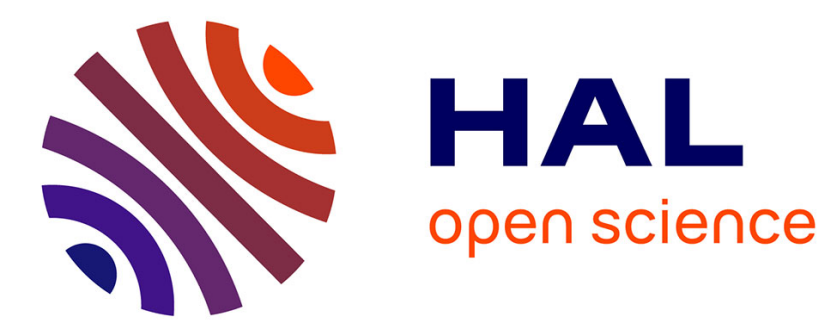

\title{
Low Frequency Amplitude - Dependent Relaxation in Cu-Al-Ni Crystals
}

S. Kustov, S. Golyandin, J. van Humbeeck, R. de Batist

\section{To cite this version:}

S. Kustov, S. Golyandin, J. van Humbeeck, R. de Batist. Low Frequency Amplitude - Dependent Relaxation in Cu-Al-Ni Crystals. Journal de Physique IV Proceedings, 1996, 06 (C8), pp.C8-321-C8324. 10.1051/jp4:1996870 . jpa-00254678

\section{HAL Id: jpa-00254678 https://hal.science/jpa-00254678}

Submitted on 1 Jan 1996

HAL is a multi-disciplinary open access archive for the deposit and dissemination of scientific research documents, whether they are published or not. The documents may come from teaching and research institutions in France or abroad, or from public or private research centers.
L'archive ouverte pluridisciplinaire HAL, est destinée au dépôt et à la diffusion de documents scientifiques de niveau recherche, publiés ou non, émanant des établissements d'enseignement et de recherche français ou étrangers, des laboratoires publics ou privés. 


\title{
Low Frequency Amplitude - Dependent Relaxation in Cu-Al-Ni Crystals
}

\author{
S. Kustov, S. Golyandin, J. Van Humbeeck* and R. de Batist** \\ A.F. Ioffe Physical-Technical Institute, Russian Academy of Sciences, Politekhnicheskaja 26, \\ St. Petersburg, Russia \\ * Dept. MTM, Katholieke Universiteit Leuven, de Croylaan 2, Heverlee 3001, Belgium \\ ** IMS, University of Antwerpen (RUCA), Middelheimlaan 1, Antwerp 2020, Belgium
}

\begin{abstract}
Pronounced peculiarities of the frequency and amplitude dependences of the amplitude-dependent internal friction have been revealed in martensitic $\beta_{1}^{\prime}$ phase of quenched $\mathrm{Cu}-\mathrm{Al}-\mathrm{Ni}$ single crystals at temperatures 200-340 K. These peculiarities were not observed in $\beta_{1}^{\prime}$ phase for crystals, subjected to ageing in austenite. Application of several experimental techniques, one of which enabled to observe directly a reversible anelastic strain during amplitude-dependent internal friction measurements, allowed to attribute the observed peculiarities of the frequency dependence in quenched samples to relaxation phenomena due to an interaction of mobile partial dislocations with mobile pinning obstacles.
\end{abstract}

\section{INTRODUCTION}

Existing theories [1,2] consider high mobility of linear and planar internal defects (dislocations, intervariant interfaces, twin boundaries) of a martensitic phase as a main source of a high intrinsic amplitude-dependent internal friction (ADIF). Purely hysteretic (frequency independent) type of the ADIF in martensite is postulated in theories [1,2] and is generally agreed upon (see, for example, review [3]). However, the conclusion about frequency independence of the ADIF in martensitic phase appears to contradict to a time dependence of the intrinsic amplitude-dependent internal friction [4]. Detailed investigations have revealed that frequency dependence of the intrinsic ADIF in martensitic phase of Cu-Al-Ni crystals does exist [5]. At room temperature, the most pronounced frequency dependence in quenched crystals was claimed to be determined mainly by an interaction of mobile partial dislocations in $\beta_{1}{ }^{\prime}$ martensite with mobile short range point obstacles (PO) $[5,6]$.

Dislocation-mobile PO interaction is considered at the origin of various relaxation phenomena: Sncek-Köster, Hasiguti peaks, relaxation due to pipe diffusion. Thus, provided PO pinning partial dislocations in $\beta_{1}{ }^{\prime}$ martensitic phase are mobile, one can expect relaxation due to the PO mobility in the frequency domain.

The results of investigations, at different frequencies and temperatures, of the intrinsic ADIF in $\beta_{1}{ }^{\circ}$ martensitic phase of $\mathrm{Cu}-\mathrm{Al}-\mathrm{Ni}$ crystals, subjected to different heat treatments, combined with direct highresolution observation of the reversible anelastic strain will be reported in the present paper.

\section{EXPERIMENTAL}

Single crystals Cu-13.2wt.\%Al-4.0wt.\%Ni with $\mathrm{M}_{s}$ and $\mathrm{A}_{\mathrm{s}}$ temperatures, as determined by DSC, equal to 370 and $363 \mathrm{~K}$, respectively, were investigated. Rod-shaped crystals $4 \mathrm{~mm}$ in diameter had [100] $\beta$-phase orientation. Samples were quenched into water from $1173 \mathrm{~K}$. A number of samples were aged after quenching in an oil bath at $473 \mathrm{~K}$ for 240 min. DSC revealed presence of $\beta_{1}^{\prime}$ phase in the quenched and aged samples. Frequency and amplitude dependences of the ADIF were measured using Dynamic Mechanical Analyser (DMA), DuPont model 830, at temperatures in a range $200-340 \mathrm{~K}$. Rectangular bars $\sim 1.0 * 4.0 * 40 \mathrm{~mm}$ were loaded in bending at frequencies $0.001-20 \mathrm{~Hz}$. In some cases during a set of the DMA tests, samples were slightly prestrained in bending up to a sag of $\sim 0.1 \mathrm{~mm}$

The second technique used direct registration of stress-strain hysteretic loops during cyclic loading of the samples at ambient temperatures and allowed to obtain simultaneously the amplitude dependence of the 
decrement, Young modulus defect and corresponding stress-anelastic strain hysteretic loops [5]. A hydraulic testing machine with a capacity strain gauge (resolution approx. $10^{-8}$ ) was used for loading in compression cylindrical samples of $4 \mathrm{~mm}$ in diameter, $11 \mathrm{~mm}$ in length, at frequencies $0.001-1.0 \mathrm{~Hz}$ and strain amplitudes $5 * 10^{-6}-10^{-4}$. More experimental details have been reported in [5].

\section{RESULTS AND DISCUSSION}

Fig. 1 shows amplitude dependences of the decrement for a quenched sample, measured at temperatures between 200$340 \mathrm{~K}$. The increase of the temperature leads to a drastic change of the type of hysteresis in the amplitude dependences (the ADIF on the reverse run during strain amplitude decrease is higher than on the direct one) and to a considerable increase of the ADIF. The largest amplitude hysteresis at $200 \mathrm{~K}$ is revealed at the lowest stress amplitudes. Measurement at $293 \mathrm{~K}$ shows the largest amplitude hysteresis with a maximum on the reverse run. Further increase of the temperature up to $340 \mathrm{~K}$ leads to the highest values of damping, but decreases the amplitude hysteresis, as compared to the one at $293 \mathrm{~K}$. The ADIF at $200 \mathrm{~K}$ increases notably with prestrain. However, the different type of the amplitude hysteresis, as compared to ambient and elevated temperatures, is preserved.

Fig. 2(a) shows the influence of the number of runs (thereby changing the strain amplitude for run 5) on the frequency spectra of the ADIF at $293 \mathrm{~K}$ for the quenched sample. Curves $1-7$ represent 7 consecutive measurements of the $A D I F$ frequency spectra. Measurements during runs $1-4$ and 6 were conducted at a stress amplitude, corresponding to the amplitude-dependent range. Run 5 corresponds to the frequency dependence of the decrement at low stress



Figure 1: Stress amplitude dependence of the decrement for a quenched sample, taken by means of the DMA at frequency $0.5 \mathrm{~Hz}$ at temperatures 200,293 and $340 \mathrm{~K}$; prestrained sample was cooled to $200 \mathrm{~K}$ in $2 \mathrm{~min}$. after deformation at $293 \mathrm{~K}$;

Sequence of measurements:

$340 \mathrm{~K}, 200 \mathrm{~K}, 200 \mathrm{~K}$ after prestrain, 293K;

Figure 2: Frequency dependence of the decrement, measured by means of the DMA:

a) a quenched sample at $293 \mathrm{~K}$ in 7 consecutive runs at stress amplitudes 3.2MPa (runs 1-4,6,7) and 0.4 $\mathrm{MPa}$ (run 5);

b) a quenched sample at temperatures 200,293 and $340 \mathrm{~K}$ and stress amplitude 3.2MPa;

Data were taken immediately after the measurements of the amplitude dependences in fig. 1

c) an aged sample at temperatures 200,293 and $340 \mathrm{~K}$ and stress amplitude 1.3 MPa;

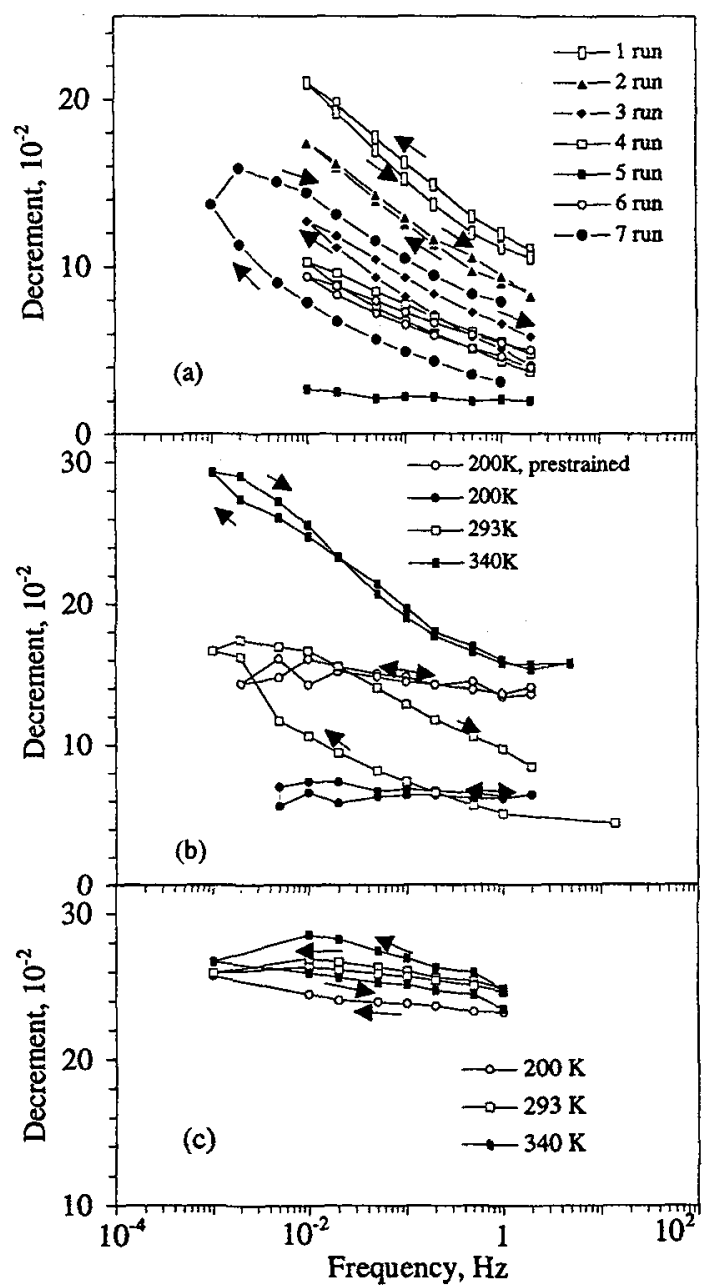


amplitude. During run 7 the lowest frequency was reduced to $0.001 \mathrm{~Hz}$. Considerable increase of the ADIF with frequency decrease is evident for all the measurements only at high stress amplitude (runs 1-4,6,7), allowing to attribute frequency dependence of the decrement to the amplitude-dependent part of the total damping. A significant decrease of the ADIF with the number of measurements is revealed. The change of the type of hysteresis, caused by the measurement procedure is also essential. During the first measurement (curve 1) the ADIF on the reverse run is lower, than on the direct one. In the second measurement hysteresis is rather weak (curve 2), whereas during the third and subsequent measurements the $\mathrm{ADIF}$ on the reverse run is notably higher than on the direct one.

Frequency spectra of the ADIF, measured at different temperatures for quenched and aged samples are represented in Fig. $2(\mathrm{~b}, \mathrm{c})$. For the quenched sample a drastic change of type of the frequency spectra with temperature is evident. The ADIF is essentially frequency independent at $200 \mathrm{~K}$. The absence of notable frequency dependence at $200 \mathrm{~K}$ is observed also for the sample, after prestrain although the decrement increased considerably. At $293 \mathrm{~K}$ the $\mathrm{ADIF}$ becomes strongly frequency dependent and exhibits pronounced hysteresis during the measuring procedure. The $\mathrm{ADIF}$ is the highest at $340 \mathrm{~K}$, but the hysteresis during the measurement vanishes. Only a minor increase of the ADIF and amplitude hysteresis with temperature is evident for the aged sample.

Qualitatively and quantitatively same regularities were revealed in amplitude and frequency spectra of the $\mathrm{ADIF}$ for quenched and aged samples at room temperature by means of the direct registration of the hysteretic loops.

Detailed investigations of the amplitude dependences of the internal friction and anelastic strain in $\beta_{1}^{\prime}$ martensitic phase of $\mathrm{Cu}-\mathrm{Al}-\mathrm{Ni}$ crystals after different heat treatments have been performed at ambient termperatures $[5,6]$. The ADIF behaviour observed was accounted for mainly by a mobility of partial dislocations from a standpoint of an unlocalised friction concept (continuous pinning-depinning of dislocations). The conclusion has been drawn that ageing in $\beta$-phase of the quenched samples leads to a change of the main obstacles for the partial dislocation motion. In the quenched samples rather mobile at room temperature short-range pinners form atmospheres. Ageing in $\beta$-phase is responsible for a drastic decrease of the mobile pinner concentration and to a formation of immobile $\gamma$-precipitates, which become major obstacles (for a not too high frequency), impeding partial dislocation mobility.

All the regularities observed for the quenched samples can be fairly well explained from the above standpoint by the action of several mechanisms: i) formation of mobile PO atmospheres pinning the dislocation at rest; ii) competitive depinning of moving dislocations from mobile $\mathrm{PO}$ and mobile $\mathrm{PO}$ drag. The former process determines the time dependence of the ADIF in quenched crystals after quenching or prestrain. The latter competition is responsible for the details of the amplitude hysteresis, temperature dependence of the ADIF in quenched crystals. A large number of the experimental details provides evidence for the relaxation nature of the peculiarities observed for the quenched crystals. For instance, the influence of the temperature on the frequency spectrum of the ADIF indicates a transition from a barely mobile state to the highly mobile one: the frequency dependence and hysteresis in frequency dependence of the ADIF is absent at low temperatures $(200 \mathrm{~K})$, when PO mobility is relatively low; the most pronounced amplitude and frequency hysteresis occurs at $293 \mathrm{~K}$, when PO mobility approaches the dislocation mobility, and, finally, the highest temperature dependence and the lack of the hysteresis is revealed in frequency dependence at $340 \mathrm{~K}$, when $\mathrm{PO}$ are sufficiently mobile to move together with dislocations in each loading cycle. The transition from $\mathrm{PO}$ depinning do dragging at room temperature is directly illustrated in fig. 3. None of these regularities are revealed in the aged samples due to the much lower concentration of the mobile PO. Mechanism of the ADIF in aged samples at low frequencies is largely purely hysteretic, frequency and temperature independent and originates, following $[5,6]$ from the long-range dislocation interaction with stress fields of precipitates.

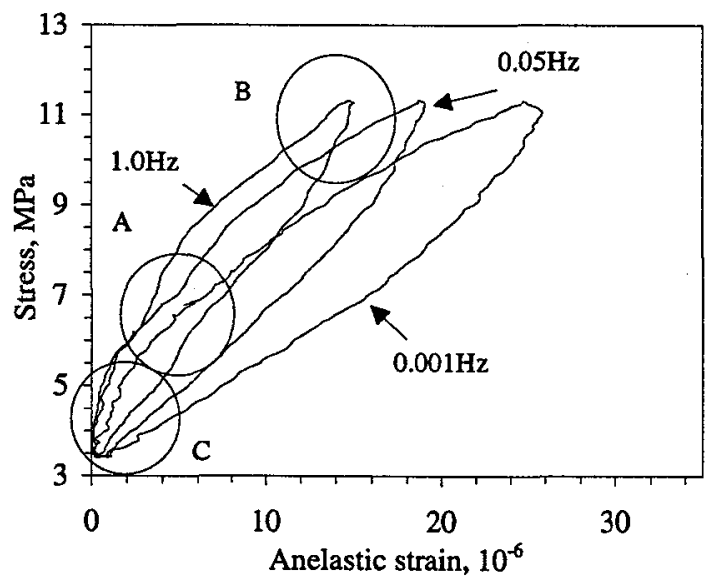

Various dislocation-related relaxation phenomena Figure 3: Stress-anelastic strain hysteretic loops for a due to the dislocation interaction with mobile PO (Snoek- quenched crystal at frequencies 1.0, 0.05 and $0.001 \mathrm{~Hz}$ and stress amplitude 3.8 $\mathrm{MPa}$; 

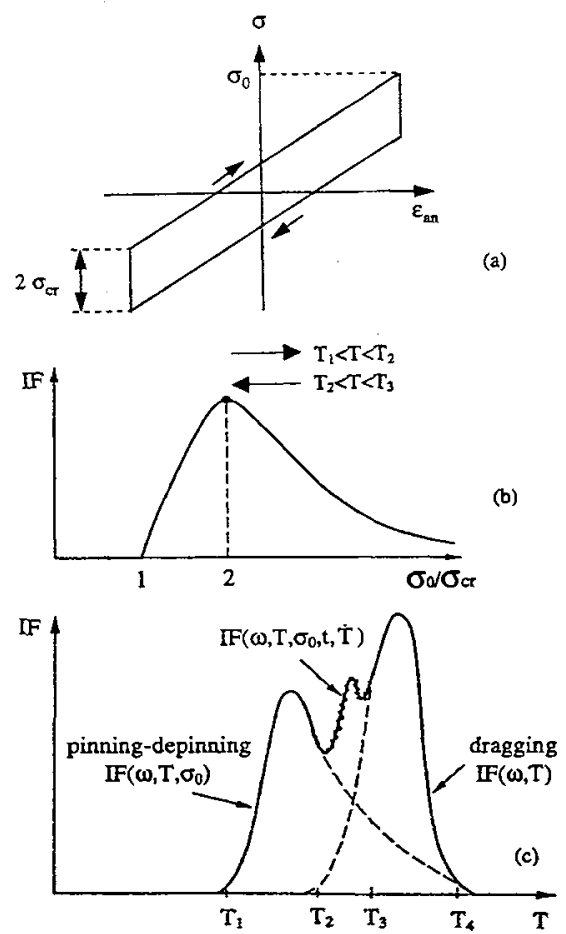

Figure 4: A qualitative model for the formation of an amplitude-dependent relaxation maximum due to PO mobility [7].
Köster, Hasiguti peaks, relaxation due to a pipe diffusion of $P O$ ) consider a single dislocation segment (kink) interacting with mobile PO. An alternative theoretical approach implies a competition between depinning and dragging for the continuous pinningdepinning of a dislocation line from PO [7]. Formation of a relaxation maximum of that type in temperature domain is represented schematically in fig. 4 [7]. Fig. 4(a) depicts a stress-anelastic strain hysteretic loop corresponding to this model. Fig. 4(b) represents schematically stress amplitude dependences of the internal friction. Relaxation internal friction maxima in the temperature domain are shown in fig. 4(c). In the temperature range $T_{1}<T<T_{2} \quad P O$ are immobile and enhanced depinning of dislocations at higher temperatures results in an increase of the $\sigma_{0} / \sigma_{0 \mathrm{co}}$. Appearance of the amplitude -dependent internal friction maximum is evident from fig. 4(b). In a temperature range $T_{2}<T<T_{3} P O$ become mobile. Formation of pinning atmospheres of $\mathrm{PO}$ leads to a decrease of $\sigma_{0} / \sigma_{0 \mathrm{r}}$ and the appearance of the next amplitude-dependent relaxation maximum according to the scheme in fig. $4(\mathrm{~b})$. The ADIF behaviour in this temperature range is the most complicated, dependent on time (number of cycles), frequency, heating or cooling rate. That relaxation corresponds to the data of the present investigation. Further temperature increase leads to an increase of PO mobility and inhibiting of the depinning for sufficiently high temperatures (low frequencies). The third amplitude-independent peak, between $T_{3}$ and $\mathrm{T}_{4}$ temperatures corresponds to the pure drag of mobile PO. Clearly, the same analysis might be performed in a frequency domain.

\section{CONCLUSIONS}

Pronounced frequency, temperature, strain amplitude and time dependence of the intrinsic internal friction in martensitic $\beta_{1}{ }^{\prime}$ phase of quenched $\mathrm{Cu}-\mathrm{Al}-\mathrm{Ni}$ single crystals has been revealed in the present study.

The peculiarities in frequency spectra of the amplitude-dependent internal friction are extremely sensitive to the details of the experimental procedure and are attributed to the relaxation phenomena due to mobility of pinning point obstacles. Observed regularities correspond to the qualitative model [7].

The mobility of point obstacles activates in a certain temperature-frequency range a number of competitive processes, including:

- formation of pinning atmospheres of mobile PO near immobile dislocations;

- redistribution of these atmospheres, when dislocations move;

\section{References}

[1] W. Dejonghe, R. De Batist, L. Delaey, Scripta Met., 10, 1125 (1976).

[2] S. Koshimizu, W. Benoit, J.de Phys., 43, Coll. C4, C4-679 (1982).

[3] J. Van Humbeeck, J. Stoiber, L. Delaey and R. Gotthardt, Z. Metallkunde., 86, 176 (1995).

[4] J. Van Humbeeck, L. Delaey, Joum. de Phys., 43, C4-691 (1982).

[5] S.B. Kustov, J. Van Humbeeck., I. Hurtado, S.N. Golyandin, R. De Batist, Proceedings of the International Symposium "M3D3", Norfolk, USA, November 1995, ASTM STP N 1304, in print.

[6] S.B. Kustov, S.N. Golyandin, I. Hurtado, J. Van Humbeeck, R. De Batist., Journ. de Phys.IV, Coll. C8, Suppl. Journ. de Phys. III, 5, C8-943 (1995).

[7] G. Gremaud, to be published. 